\title{
Antecedentes da fluoretação das águas de abastecimento público no município de Porto Alegre
}

\author{
Eduardo R. Corrêa de Barros*
}

\begin{abstract}
RESUMO
O autor apresenta uma revisāo histórica dos principais eventos que antecederam o início da fluoretação das águas de abastecimento público no município de Porto Alegre, capital do Estado do Rio Grande do Sul - Brasil.
\end{abstract}

\section{SUMMARY}

The author presents an historical review of the main events that preceed the beggining of the public waters fluoridation in Porto Alegre, the capital os the Rio Grande do Sul State, in Brazil.

\section{INTRODUÇÃO}

$O$ processo de fluoretação das águas de abastecimento público no município de Porto Alegre iniciou-se a 23 de setembro de $1975(23,28)$. Uma análise histórica dos fatos que antecederam este evento, que levou cerca de 31 anos para se efetivar, permite que se perceba um conjunto de nuances que apresentam correlaçăo com o modo como o processo passou a ser desenvolvido depois de implantado (2)

\section{DESENVOLVIMENTO HISTÓRICO}

Porto Alegre é considerada como a primeira cidade brasileira a estudar, oficialmente, o processo de fluoretaçăo de águas de abastecimento público. Esse nosso marco básico da fluoretação situa-se no ano de 1944, com um movimento iniciado pelo Dr. Breno Futuro, que elaborou e apresentou à Prefeitura Municipal, um estudo para a fluoretação das águas de abastecimento público da capital gaúcha $(17,30)$. A proposta do Dr. Breno embasava-se no conhecimento que sistematicamente vinha se acumulando, desde 1916, sobre a ocorrência natural de flúor $\theta$ de seus efeitos, sobretudo na prevençăo da cárie dental, quando em dosagem adequada; assim como no projeto norteamericano de introduzir a fluoretaçăo artificial das águas, já no ano seguinte (1945) em Grand Rapids, no estado de Michigan.

A despeito dos esforços do Dr. Breno e de outros interessados, o projeto gaúcho năo evoluiu enquanto que em janeiro de 1945 efetivamente se instalava 0 de Grand Rapids. A semente, contudo, estava plantada $(16,31)$. Neste mesmo ano, o Dr. Waldemar Pinheiro Cantergi, Químico, através de relatório do primeiro ano de atividades do "Serviço de Laboratórios da Diretoria de Saneamento" da Secretaria de Obras Públicas do Estado do RS, relatou o desenvolvimento dos estudos norteamericanos sobre o processo $(17,19)$.

Em 1950, o mesmo Dr. Cantergi, que sempre se mostrou um incansável estudioso, pesquisador e defensor da fluoretação, teve a iniciativa de efetuar a determinação do teor de flúor natural nas águas de abastecimento público das cidades gaúchas; conhecimento essencial para a dosagem do flúor a ser adicionado. É um trabalho de imenso fôlego, que resultou no mapeamento das águas estaduais. 110 localidades tiveram suas águas analisadas, observando-se que a quase totalidade apresentou valores muito baixos de ocorrência de flúor natural. A dosagem mais frequente foi $0,15 \mathrm{ppm}$ até o máximo de 0,30 ppm. Apenas 4 localidades se constituíram em exceçōes por dosagens mais elevadas: uma com 0,40 duas com 0,50 e outra com 5,5 ppm. No outro extremo, 10 localidades nāo apresentaram qualquer teor de flúor em suas águas (9).

Em 1951, a Associaçảo Pelotense de Cirurgiōes-Dentistas solicitou o início da fluoretação no município de Pelotas. Um ano após, por ocasiāo da "la Semana Odontológica do Rio Grande do Sul", na mesma localidade, o plenário aprovou a decisão de a cidade de Pelotas ser dotada de Serviço de fluoretação de águas, como medida de combate à cárie dental (17).

Em 1954, a Sociedade de Medicina do RS criou uma comissão destinada especialmente a estudar $O$ assunto (17).

Em 1955, uma ampla movimentação se desenvolveu:

- a Sociedade de Odontologia do RS e o Sindicato dos Odontologistas iniciaram atividades formais em prol da fluoretação;

- a Faculdade de Odontologia da UFRGS desenvolveu um encontro com a Fundaçāo SESP, a Secretaria de Obras Públicas e o Departamento Estadual de Saúde, com vistas à análise da viabilidade de início da utilização do método. A Secretaria de Obras Públicas adquiriu dois aparelhos fluoradores $(17,21)$.

Em 1956, os Vereadores Derly Chaves e Ney Ortiz Borges apresentaram à Câmara Municipal de Porto Alegre, indicaçōes sobre a questão da fluoretação das águas. No plano estadual, o Deputado Joảo Caruso apresentou um Projeto de Lei tornando obrigatória a fluoretação das águas nas estaçōes de tratamento do governo. $O$ deputado Onil Xavier apresentou uma emenda a fim de que o estado, em convênio com os municípios, promoves-

* Professor Titular do Departamento de Odontologia Preventiva e Social da Universidade Federal do Rio Grande do Sul.
R. Fac. Odontol.

Porto Alegre

Porto Alegre

V. 32

N. 2

NOVEMBRO

1991 
se o mesmo processo nas estaçōes municipais $(17,19,21)$.

Em 18 de junho de 1957, foi aprovada a Lei Estadual No 3.125, que "TORNA OBRIGATÓRIA A FLUORETAÇĀO DAS ÁGUAS DE ABASTECIMENTO PÚBLICO PELAS ESTAÇŌES MANTIDAS PELO ESTADO". Também ficava autorizado o poder executivo a estabelecer convênios com os municípios a fim de promover a fluoretaçāo nas estaçōes municipais (14). O Rio Grande do Sul passava a ser o primeiro estado brasileiro a contar com legislaçăo específica sobre a fluoretaçāo das águas de abastecimento público (10, 18). Logo a seguir, o Governador Ildo Meneghetti constituiu uma comissão formada pelos Drs. Flávio António Luce (Cirurgiāo-Dentista), Paulo de Oliveira Chaves (Cirurgiāo-Dentista) e Waldemar Pinheiro Cantergi (Químico), para elaborarem ante-projeto de regulamentaçāo da Lei $3.125(17,21)$. Em 18 de setembro desse mesmo ano, foi assinado o Decreto 8.169 , que regulamentava essa Lei. $\mathrm{Pe}$ lo mesmo foi criada também a COMISSĀO DE FLUORAÇĀO DAS ÁGUAS (14). Para fecho de um ano tāo profícuo para a prevençăo da cárie dental, em $1^{\circ}$ de outubro teve início o processo na primeira cidade do Rio Grande do Sul: TAQUARA (14, 17, 19, 21, 30).

Em 1958, a 28 de março, instalou-se, oficialmente, a Comissão de Fluoraçāo das Águas, com vínculo direto ao Secretário Estadual de Obras Públicas. Sob a Presidência do Prof. Flávio Luce, compunham a comissão o Eng. Otaviano de Paula Figueira, o Químico Waldemar Cantergi $\theta$ o Médico Carlos Carone. Na suplência ficaram o C. Dentista Paulo Chaves, o Eng. Pedro da Silva Souza, a Química Alpha da Rosa Teixeira e o Médico Danilo Davi $(3,19)$. É o início de um período de muito trabalho por parte da Comissảo, que se extende praticamente por todo o seu período de existência. Sem desmerecer a figura de qualquer um de seus componentes há que se ressaltar a figura do Prof. Flávio Antônio Luce como o grande batalhador, estudioso e incentivador do uso do flúor. O carinhoso apelido de "Doutor Flúor", caracteriza bem o seu denodo e pertinácia nessa cruzada. O trabalho da Comissāo liderada por Luce assumiu tal valor técnico e cientifico que, como bem lembra Cantergi (10): "colocou o Rio Grande do Sul na Iiderança da fluoretaçāo em toda a América Latina". Mais tarde, já em 1965, em encontro realizado em Caracas, na Venezuela, o Dr. Nestor Borazzarto, entusiasmado, adjetivava Luce de "Papa Flúor".

Ainda neste ano de 1958 foi implantado o sistema na cidade de GUAíBA $(17,19)$.

Em janeiro de 1959 foi implantada a fluoretaçāo em MONTENEGRO. Participante do VII Congresso Odontológico Brasileiro, o Prof. Luce afirmava (17): "Ao lado dos estudos para a ampliação dos serviços de fluoretaçāo, nossa Comissāo também tem se preocupado com o produto químico, desde uma vez que o usado atualmente é estrangeiro e o preço tem se elevado muito no último ano. Pensando nisso, realizamos uma reunião com a Federaçāo e o Centro das Indústrias do RS, no sentido de incentivar a industrializaçāo de sub-produtos de nossas indústrias de fosfatos e também do aproveitamento do minério de flúor, a fluorita, com que nosso país é rico. Desta maneira iremos baratear os custos e tornar possível a realização de nosso objetivo que é dotar todas as hidráulicas do nosso Estado de serviços de fluoração". Infelizmente, a visão de Luce nāo foi avante. Mesmo com algumas experiências bem sucedidas com a fluorita, o processo não ganhou corpo, assim como a industrialização de sub-produtos de fosfatos nāo ocorreu até hoje.

Em julho de 1960, por ocasiāo do I Congresso Brasileiro de Engenharia Sanitária, no Rio de Janeiro, Paulo de Oliveira Chaves (13), outro de nossos baluartes no trabalho da Comissāo de Fluoração, Sanitarista e pensador, lembrava com toda a propriedade que:

- "a execução da fluoração das águas de consumo público deve constituir-se em atribuição dos serviços de águas;

- os projetos de fluoraçāo das águas devem ser acompanhados dos respectivos estudos sobre a prevalência da cárie dentária na comunidade;

- controle epidemiológico da cárie dentária deve ser cominado ao respectivo serviço de saúde pública estadual; e

- as estatísticas dentais devem ser padronizadas em todo o país".

Assim como as sugestōes de Luce (17), que nāo encontraram $\Theta c \circ$, a orientaçāo de Chaves (13) também nāo foi seguida, resultando no caótico quadro de desenvolvimento que tivemos oportunidade de analisar anteriormente (2).

Em 1962, o Prof. Claudio Ferreira de Mello organizou, em Pelotas, o II Simpósio Estadual de Flúor (6). Neste mesmo ano foi organizado o Departamento Municipal de Águas e Esgotos: DMAE, em Porto Alegre (25).

Em 1964, a Federaçāo Dentária Internacional reconheceu o Rio Grande do Sul como tendo o direito ao título de "o primeiro estado a introduzir a fluoretaçāo obrigatória" (4).
Em 1965, graças a decidida atuação da Comissāo de Fluoraçāo, 71 sistemas estavam implantados e em operaçāo em cidades do RS. Como afirmava Cantergi (25) - "era o maior serviço de fluoração fora dos Estados Unidos". A capital do Estado, contudo, ainda não contava com esse benefício. O DMAE, órgāo responsável no plano municipal, nảo contava com convênio com o governo estadual. Questionado o executivo municipal, o então Prefeito Célio Marques Fernandes anunciou que: "sua administraçăo adotará imediatas providências para que seja ministrado flúor nas águas de todas as hidráulicas da cidade" (5). Isso nāo aconteceu!

Em 1967, como resultado de reestruturaçāo no executivo estadual, foi criada a Companhia Riograndense de Saneamento (CORSAN), encarregada do tratamento das águas da maioria dos municípios do interior do Estado. Nas palavras do exgovernador Jair Soares (30) - "um órgāo que inicialmente, não demonstrou o mesmo zelo que existia em relaçāo ao já entāo programa de fluoretaçāo". Por ocasiāo do IV Congresso Brasileiro de Engenharia Sanitária, chamou a atenção o pronunciamento do Eng. Químico e Civil Millo Raffin (27), Chefe da Divisão de Tratamento da Corsan, que apresentou tese onde desaconselha o uso da fluoretaçāo, dado os seus custos dentre outros bbices. Propós estudos de outras técnicas de prevençāo da cárie e sugeriu a adoçāo de aplicaçōes tópicas com fluoreto estanoso. No plano estadual, esta é das primeiras manifestaçōes documentadas que encontramos, năo expressamente contra a fluoretaçāo, mas, introduzindo tantos obstáculos que o significado é o mesmo que ser contrário a ela. No mesmo documento, o autor, não sendo Cirurgiāo-Dentista, no afā de sugerir o uso de outra técnica como alternativa, discorreu largamente sobre elas, de forma superficial. Situaçōes parecidas foram vivenciadas com grande frequência tendo por interlocutores a Engenheiros Sanitaristas e Técnicos de Estaçōes de Tratamento de Águas da CORSAN e do DMAE. O ano de 1967 caracterizou-se, ainda, pelo desenrolar-se de uma forte crise financeira que, atingindo o governo estadual, serviu de justificativa para uma sequenciada desativaçāo dos sistemas de fluoretaçāo de várias localidades. A falta de recursos para a aquisiçāo do sal de flúor, que nāo era de responsabilidade das entidades produtoras da água potável, mas sim do governo estadual, foi apontada como a responsável pelo retrocesso (21).

Em 1968, a CORSAN (11), que implan-
R. Fac. Odontol.

Porto Alegre

V. 32

N. 2

p.18-21

NOVEMBRO

1991 
tara a fluoretaçāo desde 1958, em 63 localidades, considerando que os "sistemas năo mantiveram a efetividade da adiçăo do fluorsilicato de sódio, decide pela suspensăo de todas as adiçōes a fim de permitir um reestudo das açōes a serem desenvolvidas. Observe-se a imprecisāo dos significados dessa conclusāo a que chegou a CORSAN. S ela se refere a falta de sal para a adição, o que precisava ser reestudado? Se a referência é com os resultados, onde estāo os estudos prévios para as necessárias comparaçōes?

Paralelamente, no âmbito da mesma CORSAN, consolidava-se o desenvolvimento de estudos sobre a construção de um equipamento simplificado, de baixo custo, alta praticidade e precisāo, destinado à dosagem do flúor (11). O aperfeiçoamento que se seguiu parece ter sido importante para a re-implantação do processo.

Em 1969, ampla movimentaçăo da Comissāo de Fluoração de Águas, que via o sistema deteriorar-se, levou à aprovaçāo da Lei 5.909 (em 27 de dezembro). A mesma, elaborada por uma comissāo formada por Flávio Luce, Millo Raffin (CORSAN) e Enio Daudt (DMAE), determinava que "os recursos necessários para a fluoretação SĀO DE RESPONSABILIDADE DAS ENTIDADES PÚBLICAS OU PRIVADAS PRODUTORAS DA ÁGUA POTÁVEL" (7). Infelizmente, a nova lei, ao revogar a anterior, dissolveu a própria Comissāo de Fluoração das Águas. Também exigia a elaboraçăo de Normas Técnicas para a fluoretação.

Em 1970, a 24 de abril, é assinado o Decreto Estadual $n^{\circ} 20.253$, que regulamenta a Lei 5.909. Pelo mesmo é atribuída à Secretaria da Saúde a responsabilidade de formular as normas técnicas para a fluoretaçāo, bem como controlar a execução do processo. Renasce, no âmbito interno da Secretaria da Saúde, a ex-comissāo de fluoraçāo (30). Diversas reuniōes setorias ocorrem entre diferentes instituiçōes e o DMAE a fim de estudar a implantação do método no município de Porto Alegre. Representando a Faculdade de Odontologia da UFRGS, em reuniāo promovida pela Prefeitura Municipal, chamou-me a atençāo o fato de grande número de pessoas ligadas ao DMAE năo só NÄO estarem convictos dos benefícios da fluoretaçāo como até assumirem uma posição definitivamente contrária à implantaçāo do processo, com base em alegaçōes já de há muito afastadas cientificamente. A questāo, em verdade, transcendia aos alegados aspectos económicos. Analisando a situaçăo no plano estadual, Pinto (21) alinha com os fatores econômicos (dificuldades financeiras do
Estado) mais os seguintes: fatores administrativos (falta de compreensāo e ausência de espírito de saúde pública) e fatores relacionados a estrutura da saúde pública (pouca força da comissão de fluoraçäo) como sendo, em conjunto, os responsáveis pela situação. Acreditamos que o mesmo se aplique às observaçōes feitas com relação a postura que verificamos no DMAE nessa ocasiāo. Em palestra realizada por ocasiāo do $I^{\circ}$ ESPO, o Dr. Alfredo Cestari, Diretor do DMAE, manifestou-se publicamente favorável à fluoretaçāo; pessoal, mas nāo institucionalmente, dadas as dificuldades financeiras do órgāo. Sāo suas palavras: "Apenas fiz a apresentação dos dados à disposiçāo. Se eu aqui viesse como pessoa, ou como engenheiro, poderia dizer: - vamos fluoretar a água de Porto Alegre imediatamente. Isto, do meu ponto de vista particular que é favorável à fluoretaçăo. Mas este não é o ponto de vista do DMAE, que neste momento nāo tem condiçōes de se pronunciar porque lhe falta programaçăo a respeito" $(12,24)$. Vitor Pinto estava verdadeiramente acertado com relação a existência de fatores administrativos que colaboraram no emperramento da situaçāo!

Em 1971, por ocasiăo do $\|^{\circ}$ ESPO (25), o representante do DMAE, Sr. Enio J. Daudt, referia que:

- "o controle de um produto que leva 1 ppm deve ser muito, mas muito apurado.

- não é apenas uma questāo de despesas a mais ou a menos, a razāo de o DMAE ainda nāo colocar o flúor na água da cidade. É simplesmente uma questão de programaçāo.

- o DMAE está com uma vida económica e financeira saudabilíssima.

- o flúor é apenas uma questão de tempo. Devemos aguardar que os conselheiros do DMAE optem por uma prioridade maior.

-... se o Conselho Diretor fosse convencido dessa necessidade, talvez se pudesse mudar a programação e adotar a medida.

- o Conselho não está em condiçōes de executar a fluoretação porque NĀO FORAM BAIXADAS AS NORMAS TÉCNICAS".

Estava identificado um novo óbice que não a falta de recursos financeiros. $A$ inexistência de Normas Técnicas, exigidas por Lei, passava a ser a justificativa neecessária para o não início do processo na capital do Estado. Menos mal que para a implantação dos 71 sistemas do interior do Estado, a CORSAN não agiu assim. A falta de vontade político-administrativa era, novamente um fato evidente, confir- mado pela própria diferença de 18 anos entre a fluoretaçāo das águas entre a primeira cidade gaúcha (Taquara)e a capital do Estado.

No mesmo encontro, indignado, o Secretário Estadual de Saúde, Dr. Jair Soares exclamava: "Quem nāo paga a água, - DMAE corta a água; quem nāo pōe flúor na água, a Secretaria da Saúde vai cortar também"! (25) Nada aconteceu com o DMAE! Como fecho para o $\|^{\circ}$ ESPO foram fixadas as seguintes decisōes:

- conscientizar as autoridades responsáveis (grifo nosso) dos benefícios da fluoretaçāo;

- promover campanha de esclarecimento público; $\theta$

- começar a fluoretaçāo por Belém Novo.

$\mathrm{Na}$ verdade continuávamos, $m$ termos de Porto Alegre, praticamente na "estaca zero".

Em 1972, com a formulação das NORMAS PARA A IMPLANTAÇẢO DE SERVIÇOS DE FLUORETAÇĀO DAS ÁGUAS (29), elaboradas por Comissão específica, presidida pelo Dr. José Paulo Etzberger, da Secretaria da Saúde, parecia nāo haver outros empecilhos. Esperava-se o imediato cumprimento da Lei 5.909, tanto pela CORSAN como pelo DMAE e outras estaçōes isoladas. Restavam, no interior do Estado, apenas seis cidades com os sistemas em funcionamento. Destas e das em que o processo foi suspenso, praticamente inexistem informaçōes sobre o controle do benefício (21). A Secretaria da Saúde e do Meio Ambiente (28) do Estado, informava a realizaçāo de inquéritos em 67 localidades, sendo que em 52 delas teria havido um único levantamento de dados. Nas demais 15 localidades teriam sido desenvolvidos dois ou mais inquéritos. Os rsultados de tais trabalhos nảo estāo divulgados - assim como os dados não estāo disponíveis para análise. Reessalta-se como exceção o trabalho desenvolvido na cidade de Taquara (20) que está bem documentado e publicado.

Em 1973, a 15 de janeiro, foi assinado um acordo entre a Secretaria da Saúde e a Direçāo da CORSAN, com vistas a reimplantaçăo do processo $(28,31)$. Publicado no Diário Oficial do Estado, de 16.02 .73 (p. 7 e 8), os termos do acordo assinado pelo Secretário da Saúde, Jair de Oliveira Soares e os Diretores Presidentes e Superintendente da CORSAN, respectivamente, Telmo José Bins e Joảo Antônio Osório Martinez, atribuía a Secretaria da Saúde a responsabilidade pela aquisição e fornecimento do sal de flúor à CORSAN, que desenvolveria o processo (30). Na sequência, a Secretaria da Saúde relata a entrega, nesse ano, de 50 tonela-
R. Fac. Odontol.

Porto Alegre

V. 32

N. 2

p.18-21

NOVEMBRO

1991 
das do sal de flúor (8). Embora um acordo prático e que viabilizou a retomada do processo no Estado, deu-se ao arrepio da Lei, uma vez que cabia à CORSAN a aquisiçăo do sal, competindo à Saúde o controle e acompanhamento epidemiologico.

Em 1974, após o início do processo de "doaçăo" do sal de flúor, a CORSAN reativou 72 sistemas em municípios do interior do Estado. A 24 de maio foi aprovada a Lei Federal $n^{\circ} 6.050$, que "determina a obrigatoriedade da fluoretaçāo das águas de abastecimento público no Brasil". Em Porto Alegre, isso não ocorria, muito embora as atitudes políticas estivessem em franca execução: por ocasião do $3^{\circ}$ ESPO (26), O DMAE e a Secretaria da Saúde assinavam acordo para a fluoretação, definindo as competências de cada órgāo. Ao DMAE competia proceder a fluoretaçăo, mantendo a dosagem ótima indicada para Porto Alegre, conforme as Normas Técnicas da Saúde. Ao final do ano, nada havia mudado!

Em 1975, um debate sobre os "custos da fluoretaçăo", desenvolvido na AMRIGS (15 de maio) e divulgado pelo DMAE (22), dava conta d um custo de Cr\$ 2,91 por pessoa ao ano. Mesmo se constituindo em um valor baixo para a época (o salário mínimo mensal correspondia a Cr\$ 532,80 ), ele fol superestimado, dado que levou em conta beneficiar apenas as crianças de 7 a 14 anos ( 195.150 crianças $-19,36 \%$ do total de 1.008 .000 habitantes) quando as demais faixas etárias, sabe-se hoje à saciedade, também sảo beneficiadas. Parecia que ia reiniciar-se o ciclo com as alegaçōes econômicas.

No mês de junho, a Câmara Municipal de Porto Alegre desenvolveu um Ciclo de Palestras e Debates a fim de definir seu posicionamento a respeito da fluoretaçāo. Participando do ciclo, juntamente com Luce e outros colegas, tive a oportunidade de enfatizar a necessidade da adoçāo do método, bem como criticar o nāo cumprimento da Lei 5.909 , que atribuía a responsabilidade do custeio dessas operaçōes às entidades públicas ou privadas produtoras da água potável. Manifestei a descrença em que o fornecimento do sal pela Secretaria da Saúde se constituisse em um procedimento adequado para a total soluçăo do problema. A medida paternalista do governo estadual para com essas instituiçōes, certamente nāo as tornaria mais interessadas para a execuçăo do processo (1). De fato, mais tarde, já então como Governador do Estado, o Sr. Jair Soares $(30)$ viria a lamentar que, sendo importado o flúor, as firmas nảo cumprissem os contratos, atrasando as entregas e gerando interrupçōes no processo
(15). A falta de integração entre a Secretaria da Saúde e os Serviços de Abastecimento de Águas, seria mais um problema.

No mês de julho, a SSMA e o DMAE firmaram um contrato nos mesmo moldes do acordo que foi firmado com a CORSAN (ao arrepio da lei): o governo do Estado fornecia o sal e o DMAE executava o processo $(28,30)$

A 23 de setembro de 1975, finalmente, TEM INÍCIO O PROCESSO DE FLUORETAÇĀO DAS ÁGUAS DE ABASTECIMENTO PÚBLICO NO MUNICÍPIO DE PORTO ALEGRE $(23,28)$.

A primeira ETA do sistema do DMAE a desenvolver o processo foi a da LOMBA DO SABĀO. Seguiram-se, cronologicamente, as ETAs: São Joăo, em outubro de 1975, José Loureiro da Silva, também em outubro de 1975; Belém Novo, em janeiro de 1976; Moinhos de Vento e Tristeza, em maio de 1976 e Francisco de Lemos Pinto, em maio de 1983.

Estava implantado o processo.

Seu desenvolvimento, contudo, não seria tranquilo, como tivemos oportunidade de analisar em trabalho anterior (2).

\section{REFERÊNCIAS BIBLIOGRÁFICAS}

01. BARROS, E.R.C. de - Valor da fluoretaçāo da água potável. Anais da Câmara Municipal de Porto Alegre. IV:(junho): 93-102, 1975.

02. - Análise Crítica da Fluoretaçāo de Águas no Município de Porto Alegre/RS. Revista Gaúcha de Odontologia. 38:247-254, 1990.

03. BOLETIM DO SERVIÇO DE ODONTOLOGIA SANITÁRIA. Secretaria de Estado dos Negócios da Saúde do RS. Ano I ( $n^{\circ}$ 1), 1964.

04. - Secretaria de Estado dos Negócios da Saúde do RS. Ano I ( $\left.n^{\circ} 3\right), 1965$, p.1.

05. - Secretaria de Estado dos Negócios da Saúde do RS. Ano II (nْ 1), 1965, p.2.

06. - Secretaria de Estado dos Negócios da Saúde do RS. Ano II ( $\left.n^{\circ} 3\right), 1966$, p.8.

07. - Secretaria de Estado dos Negócios da Saúde do RS. Ano VII ( $\left.n^{\circ} 2\right), 1970$.

08. - Secretaria de Estado dos Negócios da Saúde do RS. Anos VIII, IX e X. 1971 a 1973. p. 8

09. CANTERGI, W.P. - Teor de flúor nas águas de abastecimento público das cidades do Rio Grande do Sul. Comissāo de fluoração das águas. Secretaria de Obras Públicas do Governo do Estado do RGS. 1955. 7p.

10. - Comemoração do $1^{\circ}$ decênio de fluoraçāo no Rio Grande do Sul. Bol. Serv. Odont. Sanit. IV (n० 1-2): 1-3, 1967.

11. CASTIEL, V. - Experiência prática, equipamentop simplificado de dosagem de sais de flúor em águas. Companhia Riograndense de Saneamento. 1977. 24p.

12. CESTARI, A. - Flúor nas hidráulicas de Porto Alegre. $1^{\circ}$ Encontro de Saúde Pública em Odontologia. Prefeitura Municipal de Porto Alegre, 1970.
13. CHAVES, P.O. - Controle epidemiológico da fluoretação das águas. Comissāo de fluoraçāo das águas. Secretaria de Obras Públicas do RS. 1961. 8p.

14. COMISSĀO DE FLUORAÇĀO DAS ÁGUAS. Secretaria de Estado dos Negócios das Obras Públicas - Lei 3.125, Decreto 8.169, Decreto 9.656 e Regimento Interno. $1959.10 p$.

15. COMPANHIA RIOGRANDENSE DE SANEAMENTO - Teores de flúor em, diversas unidades de saneamento. Documentos encaminhados ao CPOS. 1982 e 1983.

16. GRINPLASTCH, B.S. - Fluoretaçāo de águas no Brasil. Boletin de la Oficina Sanitaria Panamericana. (Abril): 321-330, 1974.

17. LUCE, F.A. - Fluoração das águas no Rio Grande do Sul. Rev. Gaúcha de Odont. 7:294-296, 1959.

18. - Plano Nacional de Fluoraçāo de Águas. Comissāo de Fluoraçāo das Águas do RS. $1960.14 p$.

19. - Dados sobre a Fluoração no Rio Grande do Sul. (mimeo) 1962.

20. et alii - 10 anos de fluoretaçāo das águas na cidade de Taquara. Bol. Serv. Odont. Sanit. V:(1)8-12, 1968.

21. PINTO, V.G. - Prevenção da cárie dental pela fluoretaçāo das águas de abastacimento público no Rio Grande do Sul. Curso de Saúde Pública. FSP-USP. 1972. (mimeo).

22. PREFEITURA MUNICIPAL DE PORTO ALEGRE. Departamento Municipal de Águas e Esgotos. Centro de Estudos de Saneamento Básico. Fluoretaçāo das águas. Porto Alegre, 1975. 3p.

23. - Departamento Municipal de Águas e Esgotos. - Informaçōes sobre a fluoretaçāo das águas em Porto Alegre. Gabinete do Diretor Geral do DMAE. Porto Alegre, 1988.

24. - Secretaria de Saúde e Serviço Social. $1^{\circ}$ Encontro de Saúde Pública em Odontologia. Porto Alegre, 1970.

25. - Secretaria de Saúde e Serviço Social. $\|^{\circ}$ Encontro de Saúde Pública em Odontologia. Porto Alegre, 1971

26. - Secretaria de Saúde e Serviço Social. III Encontro de Saúde Pública em Odontologia. Porto Alegre, 1974.

27. RAFFIN, M. - Fluoração de águas de abastecimento público e outros métodos de prevençāo da cárie dentária. Tese apresentada ao IV Congresso Brasileiro de Engenharia Sanitária. Julho de 1967. 12p. (mimeo)

28. RIO GRANDE DO SUL. SECRETARIA DA SAÚDE E MEIO AMBIENTE - Informaçōes sobre a fluoretaçāo no Estado. Gabinete do Sr. Secretário de Estado. Porto Alegre, 1988.

29. - Normas para a implantaçāo de serviços de fluoretaçāo das águas. Porto Alegre, 1972.

30. SOARES, J. - Programa de fluoretação das águas no Estado do Rio Grande do Sul. Seminário sobre a prevençāo da cárie dental no Brasil. Brasília. 1978 (mimeo).

31. VIEGAS, A.R. - Odontologia Sanitária: aspectos preventivos da cárie dentária. Curso de Especialização em Saúde Pública para Cirurgiōes-Dentistas. USP. Sāo Paulo. 1961. 